\title{
USE OF CORRELATION MICROSCOPY AT EVALUATION OF GOSS TEXTURE IN GOES
}

\author{
${ }^{1}$ Renáta PALUPČíKOVÁ, ${ }^{1}$ Kryštof HRADEČNÝ, ${ }^{1}$ Anastasia VOLODARSKAJA, \\ ${ }^{1}$ Vlastimil VODÁREK \\ ${ }^{1}$ VSB - Technical University of Ostrava, Ostrava, Czech Republic, EU, \\ renata.palupcikova@vsb.cz
}

https://doi.org/10.37904/metal.2021.4138

\begin{abstract}
The electromagnetic properties of strips made of grain-oriented electrical steels (GOES) are strongly affected by the sharpness of the Goss texture. The Goss texture is defined by $\{110\}\langle 001\rangle$, where the planes $\{110\}$ are parallel to the surface of the strip and the directions $\langle 001\rangle$ are parallel to the rolling direction. The formation of this texture is the result of a complex technological process, which consists of hot rolling, two-stage cold rolling, decarburization annealing and final high-temperature annealing. To date, however, the phenomenon of preferential growth of grains with a Goss orientation during secondary recrystallization has not been fully elucidated.

This work aimed to create a correlation method that will allow obtaining more data on the structure and microtexture in GOES strips. Thus, a combination of macrostructure images and electron backscattered diffraction (EBSD) analysis was studied. Cross-sections through macro samples were used for EBSD analysis. They were cut in defined areas of macro samples so that it was possible to assign EBSD results to macrostructure images and obtain simultaneous information about size and orientation of grains. The main advantage of the methodology is that using EBSD data on grain orientation, which are obtained by analysis of defined cross-sections taken from macro samples, it is possible to define very effectively the orientation of individual grains for a relatively large area of GOES strips.
\end{abstract}

Keywords: GOES, Goss texture, EBSD, correlation microscopy, macrostructure, microtexture

\section{INTRODUCTION}

Grain-oriented electrical steel (GOES) is a soft magnetic material. GOES is widely used as a core material in transformers and has excellent magnetic properties. This material contains about $3 \mathrm{wt} \% \mathrm{Si}$, which ensures a reduction of the eddy current loss [1]. GOES is characterized by a strongly preferred texture of $\{110\}\langle 001\rangle$. The direction $\langle 001\rangle$ is the easiest magnetization direction for iron [2]. The Goss texture in these steels is the result of a complex technological process that consists of hot rolling, first cold-rolling, decarburization annealing, second cold-rolling and high-temperature annealing [3]. It is believed that the formation of grains with the Goss texture in final strips has its origins already in hot rolling, where grains with this orientation are formed in subsurface layers due to shear deformation. These grains may have acted as nuclei for secondary recrystallization, this phenomenon is known as the inheritance mechanism [4]. Another uniqueness is the fact that GOES requires the use of secondary recrystallization as the only commercially used material for abnormal grain growth. As primary recrystallization, secondary recrystallization involves a nucleation process followed by grain growth. The driving force for this process is the reduction of grain boundary energy [5].

This work is focused on the use of correlation microscopy, which combines macrostructure images and EBSD analysis for a deeper understanding of relationships between size and orientation of ferritic grains. 


\section{EXPERIMENTAL PROCEDURE}

Experimental material was processed by an AIN + $\mathrm{Cu}$ industrial production technology. Strips investigated were manufactured from two slabs, one of them was cast in the middle and the other one at the end of the casting sequence. Samples for structure characterization were cut in the middle width of strips. Two samples were taken from each original slab. The size of samples A1-A4 for structure characterization was $75 \times 120$ $\mathrm{mm}$. The chemical composition of the samples investigated is given in Table 1.

Table 1 Chemical composition of the samples [w. \%]

\begin{tabular}{|l|l|l|l|l|l|l|l|l|l|}
\hline Sample & $\mathrm{C}$ & $\mathrm{Mn}$ & $\mathrm{Si}$ & $\mathrm{P}$ & $\mathrm{S}$ & $\mathrm{Cu}$ & Altotal & $\mathrm{N}_{2}$ & $\mathrm{Ti}$ \\
\hline A1, A2 & 0.0070 & 0.26 & 3.27 & 0.014 & 0.006 & 0.49 & 0.017 & 0.0138 & 0.004 \\
\hline A3, A4 & 0.0055 & 0.26 & 3.26 & 0.014 & 0.006 & 0.49 & 0.017 & 0.0142 & 0.004 \\
\hline
\end{tabular}

The experiment was based on the paper [6], where correlation microscopy was used to describe the relationship between deviations of grains from the Goss orientation and the grain size in GOES strips. The experimental methodology, therefore, consisted of revealing the macrostructure by etching and defining the areas of interest (ROI) with dimensions of approximately $25 \times 55 \mathrm{~mm}$. Cross-sections in defined positions of ROIs were cut, which were then used for EBSD analysis. Due to the abnormal grain size in GOES, samples for EBSD analysis were prepared by a sandwich method, in which cross-sections of strips were folded and embedded in resin. Figure 1 shows a flow chart of the experiment. This method makes it possible to capture a larger number of grains in EBSD analysis and at the same time makes it possible to better understand relationships between deviations from the Goss orientation and the size of ferritic grains.

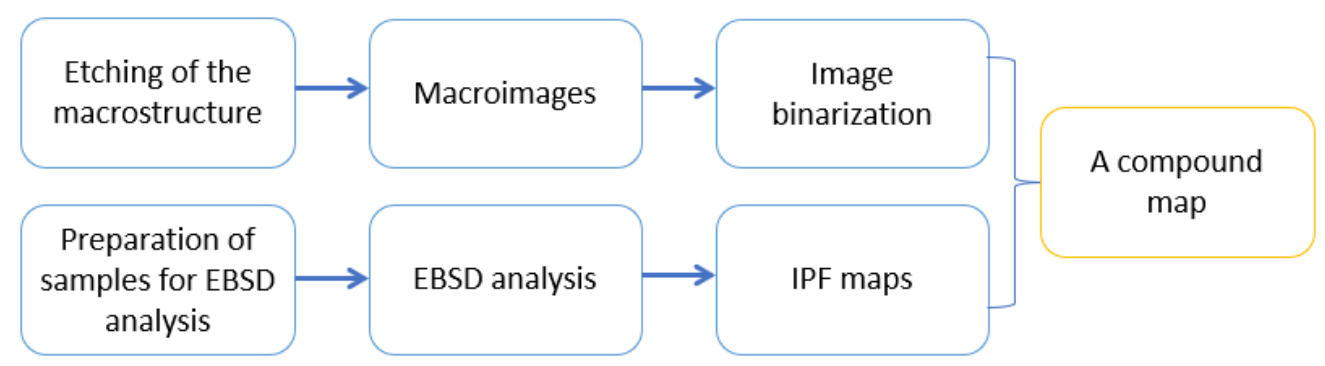

Figure 1 Scheme of experimental correlation method

Macro samples were etched in a solution of $\left(\mathrm{NH}_{4}\right)_{2} \mathrm{~S}_{2} \mathrm{O}_{8}$ [7]. The macrostructure images were binarized using Matlab software. EBSD samples were prepared by mechanical grinding and polishing. The final step of preparation was polishing on colloidal silica. Microtexture analysis was performed using the EBSD method in a FEI QUANTA FEG 450 scanning electron microscope equipped with a Hikari camera. OIM Analysis ${ }^{\mathrm{TM}}$ software was used to process the EBSD data.

\section{RESULTS AND DISCUSSION}

Figures $\mathbf{2 a}$ and $\mathbf{2 b}$ document the IPF maps for the technological directions ND (normal direction) and RD (rolling direction) of the sample $\mathrm{A} 3$, respectively. Figures $\mathbf{2 c}$ and $\mathbf{2 d}$ show the compound maps created by merging macrostructure images and IPF maps. The colourless grains are those that were not captured in the EBSD cross-sections. The IPF map for ND contained grains whose normals to the surface were close to poles $<110\rangle$. When comparing Figures $\mathbf{2 a}$ and $\mathbf{2 c}$, the grains whose orientation differed and approached poles $\langle 111\rangle$ or $\langle 012\rangle$ were generally fine. As evident from Figure $\mathbf{2} \mathbf{b}$, where the IPF map for RD is documented, most of 
the grains have reached an orientation approaching $\langle 001\rangle$. Colourless grains in the map were not included in the EBSD cross-sections.

The other studied samples also contained mainly grains whose normals to the surface approached poles $\langle 110\rangle$ and in the rolling direction they were close to poles of $\langle 001\rangle$. At the same time, they contained a number of grains whose normals approached poles $\langle 111\rangle,\langle 012\rangle$ and $\langle 133\rangle$. In the rolling direction orientations close to $\langle 001\rangle$ prevailed. However, there also were grains with orientation close to $\langle 012\rangle,\langle 111\rangle$ and $\langle 011\rangle$.

Figures 3a-3c show deviations of the individual ferritic grains from the ideal Goss orientation in the sample A3. Compared to other samples investigated, it achieved lower grain deviations from the ideal Goss texture. Although there is also a misorientation value above $30^{\circ}$, it is only associated with one grain, as can be seen from the compound map in Figure $\mathbf{3 b}$. The histogram in Figure $\mathbf{3 c}$ shows that the number fraction of grains with such a deviation is negligible. Most grains in the sample A3 reached deviations of up to $10^{\circ}$. The highest column in the histogram corresponds to a deviation of $8^{\circ}$ and represents $25 \%$ fraction of grains from the total number of analysed grains. The number fraction of grains with misorientation above $20^{\circ}$ is low. It is clear from the compound map that the grain with misorientation above $30^{\circ}$ (green one) was fine. However, grains with a deviation above $20^{\circ}$ (yellow ones) were comparable in size to many grains with a deviation from the ideal orientation $\{110\}\langle 001\rangle$ less than $20^{\circ}$ (blue and red ones).
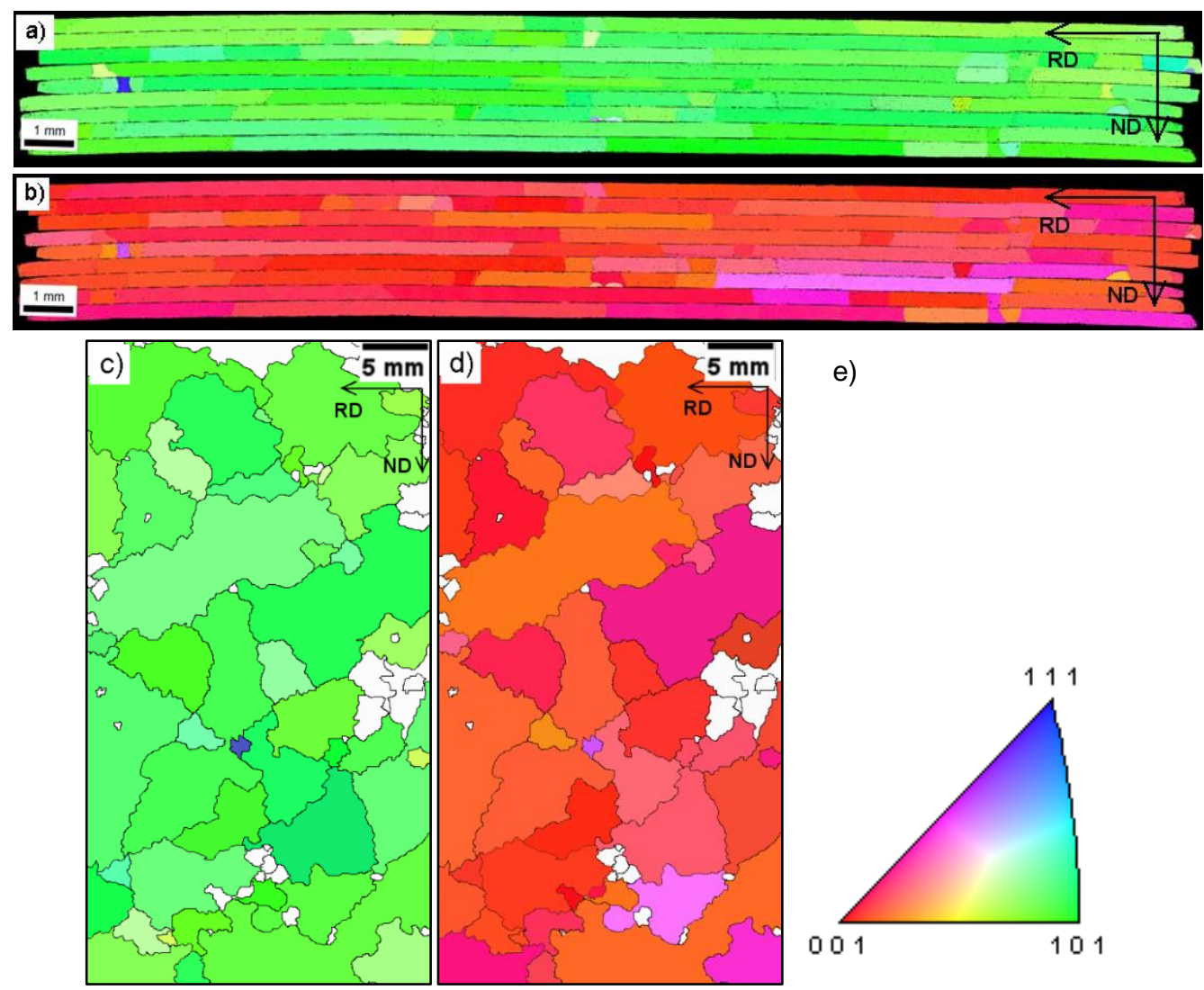

e)

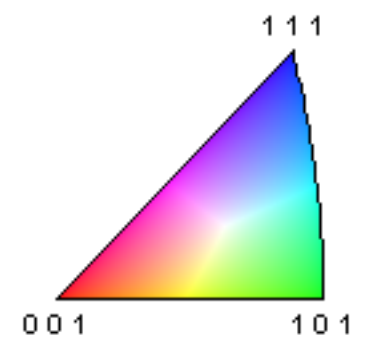

Figure 2 Results of experimental activities on the sample A4 a) IPF map for ND; b) IPF map for RD; c) a compound map created by merging of the macro image and IPF map for ND, d) a compound map created by merging of the macrostructure image and IPF map for RD; e) legend for colour coding of IPF maps

Figures $\mathbf{4 a - 4 d}$ show deviations of grains from the Goss texture in samples evaluated. These histograms show a number fraction as a function of grain misorientation. Colour coding corresponds to grain misorientations in an interval of ten degrees, e.g. blue colour characterizes misorientation in the range $0-10^{\circ}$, etc. The results of the microtexture analysis showed that all samples contained grains whose misorientation exceeded $10^{\circ}$. A 
more thorough study of the macrostructure of strips did not reveal a relationship between size and orientation of grains. Grains of various sizes reached high values of deviations, especially in the case of samples A1 and A2, in which deviations of some grains reached values of up to $50^{\circ}$.

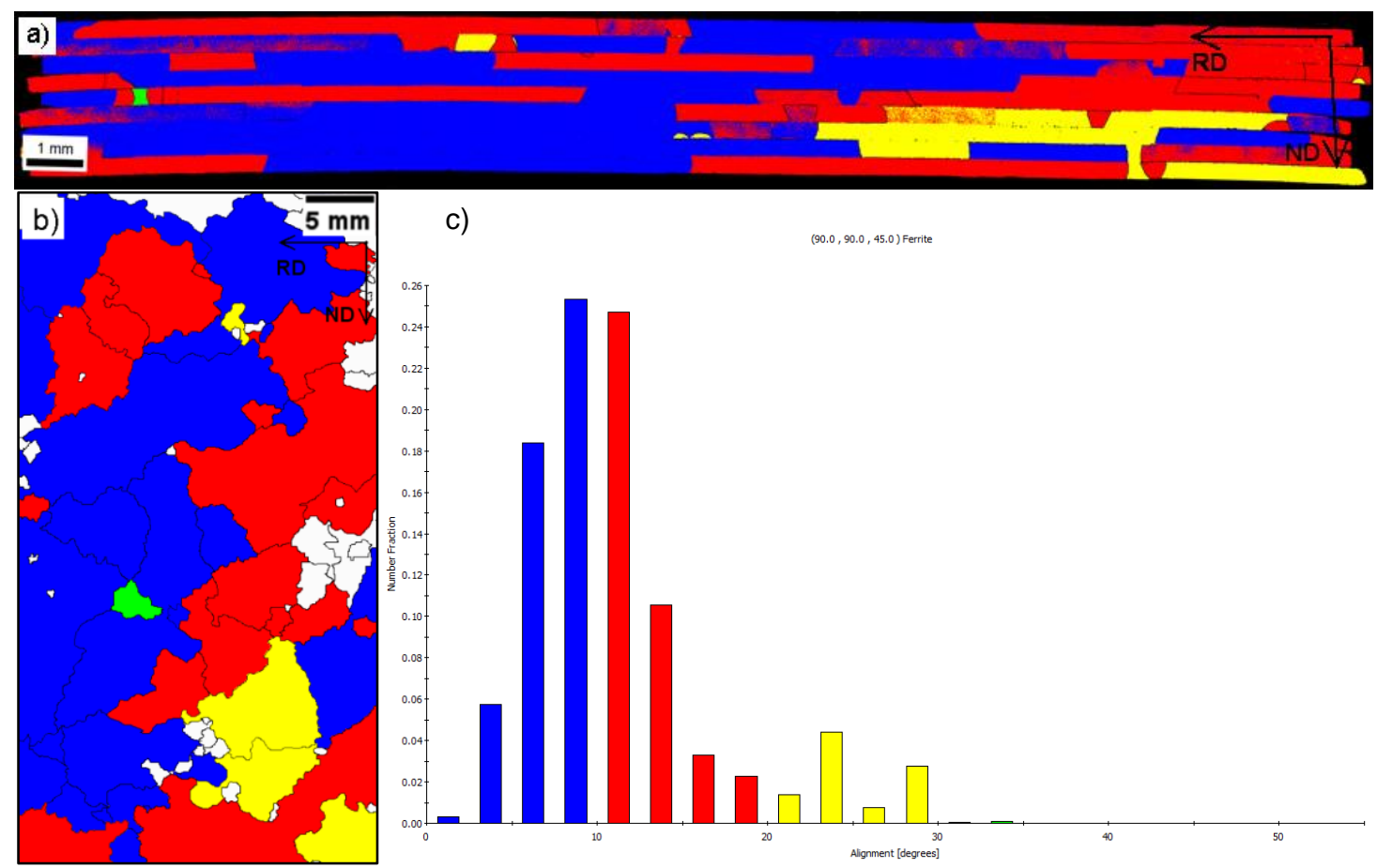

Figure 3 a) Visualization of misorientation of individual grains in the sample A3 from the ideal Goss texture; b) a compound map created by merging of the macrostructure image with the visualization of the grain misorientation from the Goss texture; c) histogram of grain deviations from the ideal Goss texture and corresponding colour coding
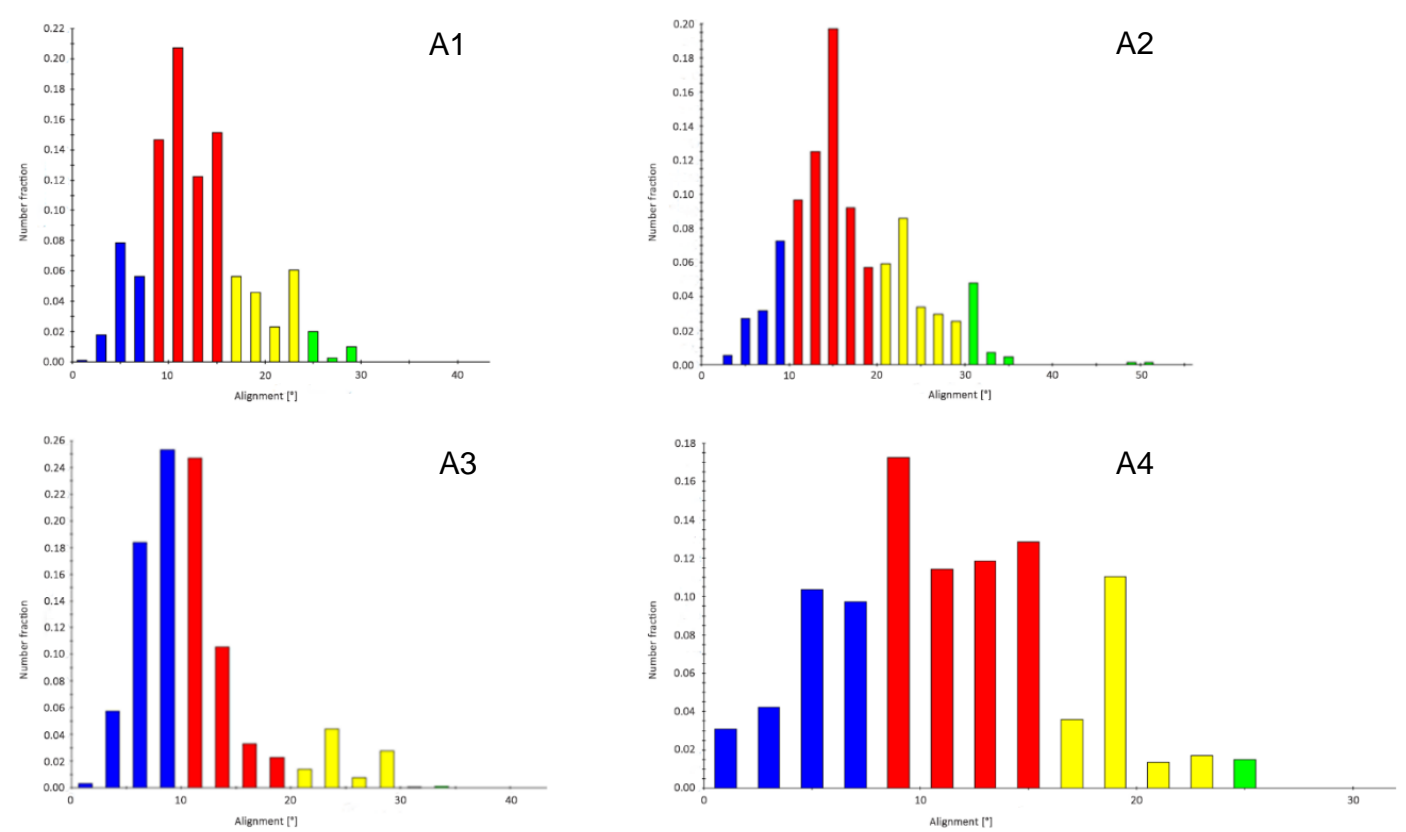

Figure 4 Histograms of grain deviations from the ideal Goss orientation and corresponding colour coding for samples A1-A4 
Table 2 summarizes the misorientation of ferritic grains from the ideal Goss orientation in samples evaluated. The common value of grain misorientation from the ideal Goss texture in a standard quality GOES is up to $11^{\circ}$ [8]. The average misorientation of grains in samples A1 and A2 exceeds this limit. Some grains reached a misorientation of over $50^{\circ}$. Furthermore, no direct relationship was found between the size and misorientation of ferritic grains.

According to [9] the sharpness of the Goss texture depends on factors such as the primary texture, the free surface energy of grains, particles of secondary phases and more. Therefore, the cause of high deviations from the Goss texture cannot be unambiguously determined. Secondary recrystallization is a very important process that affects the final sharpness of the Goss texture. Homma et al. [10] state that the secondary growth of grains is highly dependent on their misorientation from the Goss texture. There was a large number of grains in the samples investigated, the dimensions of which did not correspond to the standard dimensions, so it can be assumed that the process of secondary recrystallization was far from ideal.

Table 2 Number fractions of grains depending on their misorientation

\begin{tabular}{|c|c|c|c|c|}
\hline \multirow{2}{*}{ Misorientation $\left[^{\circ}\right]$} & \multicolumn{4}{|c|}{ Number fractions of grains in the sample } \\
\cline { 2 - 5 } & $\mathrm{A} 1$ & $\mathrm{~A} 2$ & $\mathrm{~A} 3$ & $\mathrm{~A} 4$ \\
\hline 1 & 0.001 & 0.000 & 0.003 & 0.030 \\
\hline 6 & 0.097 & 0.049 & 0.241 & 0.146 \\
\hline 11 & 0.410 & 0.210 & 0.500 & 0.384 \\
\hline 16 & 0.274 & 0.373 & 0.139 & 0.247 \\
\hline 21 & 0.125 & 0.155 & 0.037 & 0.160 \\
\hline 26 & 0.081 & 0.117 & 0.052 & 0.032 \\
\hline 31 & 0.013 & 0.085 & 0.028 & 0 \\
\hline 36 & 0 & 0.010 & 0.001 & 0 \\
\hline 41 & 0 & 0 & 0 & 0 \\
\hline 46 & 0 & 0 & 0 & 0 \\
\hline 51 & 0 & 0.002 & 0 & 0 \\
\hline 56 & 0 & 0 & 0 & 0 \\
\hline Number fraction of grains with misorientation up to $11^{\circ}$ & 0.508 & 0.259 & 0.744 & 0.560 \\
\hline Average misorientation $\left[^{\circ}\right]$ & 12.852 & 16.928 & 11.134 & 11.412 \\
\hline
\end{tabular}

\section{CONCLUSION}

In this paper, the methodology based on correlation microscopy was applied for investigations on the relationship between the deviations of grains from the exact Goss orientation and the grain size in final GOES strips. Studies were carried out on samples cut from strips manufactured using an AIN + Cu industrial processing technology. It has been demonstrated that the relationship between the deviation from the ideal Goss orientation and the grain size does not exist.

The experimental results show that the methodology may be successfully used for a better understanding of the microtexture development in GOES strips. The main advantage of this methodology is the fact that it allows to obtain EBSD information from a relatively large area of macro samples and to correlate the orientation and size of individual grains. 


\section{ACKNOWLEDGEMENTS}

This paper created with the contribution of the projects Student Grant Competition "SP2021/48 Optimization of the properties of advanced technical materials by control of their microstructural parameters" and "SP2021/41 Specific research in the metallurgical, materials and process engineering".

\section{REFERENCES}

[1] KIM, J. K., LEE, D. N., KOO, Y. M. The evolution of the Goss and Cube textures in electrical steel. Materials Letters. [online]. 2014, vol. 122, pp. 110-113. Available from: https://doi.org/10.1016/j.matlet.2014.01.166.

[2] DORNER, D., ZAEFFERER, S., RAABE, D. Retention of the Goss orientation between microbands during cold rolling of an Fe3\%Si single crystal. Acta Materialia. [online]. 2007, vol. 55, no. 7, pp. 2519-2530. Available from: https://doi.org/10.1016/j.actamat.2006.11.048.

[3] XIA, Z., KANG, Y., WANG, Q. Developments in the production of grain-oriented electrical steel. Journal of Magnetism and Magnetic Materials. [online]. 2008, vol. 320(23), pp. 3229-3233. Available from: https://doi.org/10.1016/j.jmmm.2008.07.003.

[4] FANG, F., LU, X., ZHANG, Y. X., WANG, Y., JIAO, H. T., CAO, G. M., YUAN, G., XU, Y. B., MISRA, R. D. K., WANG, G. D. Influence of cold rolling direction on texture, inhibitor and magnetic properties in strip-cast grainoriented 3\% silicon steel. Journal of Magnetism and Magnetic Materials. [online]. 2017, vol. 424, pp. 339-346. Available from: https://doi.org/10.1016/j.jmmm.2016.10.086.

[5] HUMPHREYS, F. J., HATHERLY, M. Recrystallization and related annealing phenomena. Elsevier, 2004.

[6] BERNIER, N., LEUNIS, E., FURTADO, C., VAN DE PUTTE, T., \& BAN, G. (2013). EBSD study of angular deviations from the Goss component in grain-oriented electrical steels. Micron, [online]. 2013, vol. 54-55, pp. 4351. Available from: https://doi.org/10.1016/j.micron.2013.08.003.

[7] PALUPČíKOVÁ, R. Use of correlation microscopy at evaluation of Goss texture in GOES. Ostrava, 2020. Master thesis. VSB-TU Ostrava.

[8] VOLODARSKAJA, A., MIKLUŠOVÁ, Š., HOLEŠINSKÝ, J., VODÁREK, V., ŽÁČEK, O. Microstructure evolution in goes during manufacturing process. In: METAL 2014 - 23rd International Conference on Metallurgy and Materials, Conference Proceedings. 2014, pp. 546-552.

[9] MORAWIEC, A. On abnormal growth of Goss grains in grain-oriented silicon steel. Scripta Materialia. [online]. 2011, vol. 64(5), pp. 466-469. Available from: https://doi.org/10.1016/i.scriptamat.2010.11.013.

[10] HOMMA, H., HUTCHINSON, B. Orientation dependence of secondary recrystallisation in silicon-iron. Acta Materialia. [online]. 2003, vol. 51(13), pp. 3795-3805. Available from: https://doi.org/10.1016/S13596454(03)00193-9. 